\title{
A NOÇÃO DE REPRESENTAÇÃO EM DURKHEIM
}

FERNANDO PINHEIRO FILHO

A publicação da última das grandes obras de Durkheim, As formas elementares de vida religiosa, em 1912, cristaliza um movimento de inflexão em sua obra que, entre outros aspectos, caracteriza-se pela passagem da consciência coletiva para as representações coletivas como conceito-chave da análise sociológica. A ênfase se desloca da morfologia social, cujo mecanismo é o principal fundamento explicativo dos fatos sociais na Divisão do trabalho social, para a valorização do simbolismo coletivo como princípio fundante da realidade social. Conforme a metáfora presente no artigo de 1911, "Julgamentos de valor e julgamentos de realidade", a mudança desloca a ênfase do corpo (morfologia) para a alma (ideais) da sociedade; dos determinantes estruturais para aquilo que era apenas produto dessa determinação. É certo que tal movimento, visível ao menos desde $O$ suicídio, de 1897, em que o autor afirma que a vida coletiva é feita essencialmente de representações, não passou despercebido pelos estudiosos da obra. No entanto, dada a importância heurística da noção, creio que um estudo sobre sua gênese contribui para esclarecer o sentido do projeto durkheimiano de superação do discurso filosófico - ou, mais precisamente, de substituição da epistemologia kantiana por uma sociologia do conhecimento. Note-se que o primeiro título aventado por Durkheim para o livro de 1912 foi "As formas elementares do pensamento e a prática religiosa", talvez mais adequado ao produto de uma reflexão em que religião e pensamento resultam co-extensivos, adquirindo a primeira $o$ caráter de meta-instituição, donde a necessidade de relacionar as crenças religiosas e cognitivas no interior de uma teoria geral das representações coletivas. Isso ajuda a explicar a organização do livro, em que o corpo do texto é inteiramente dedicado à religião, enquanto a introdução e a conclusão concentram uma argumentação atinente à redução das categorias do 
conhecimento a fenômenos sociais. Este trabalho procura, assim, acompanhar a tentativa de superação da epistemologia filosófica a partir do estudo da fonte da concepção durkheimiana de representação, qual seja, a leitura específica de Kant realizada por seus discípulos franceses, integrantes da corrente conhecida como neocriticismo. Antes, porém, é preciso acompanhar o lugar das representações coletivas na economia dos conceitos durkheimianos.

\section{HIPERESPIRITUALIDADE: AS REPRESENTAÇÕES COLETIVAS}

Durkheim pensa o conhecimento a partir da tradição da filosofia crítica e com ela, demonstrando apreço pela urdidura racional da trama dos conceitos em Kant - em si legítima embora insuficiente no diagnóstico durkheimiano, de sorte que é preciso avançar do ponto em que o kantismo se detém. Assim, tanto o filósofo como o sociólogo concordam que o conhecimento tenha um problema essencial de fundamentação racional. Dado esse piso comum, a solução durkheimiana se constitui alicerçada na definição das categorias como uma espécie do gênero das representações coletivas, identificando-as. Mas, se o inteiro significado dessa operação só pode ser recuperado à luz do legado kantiano que pretende superar, e com especial ênfase na incorporação da vertente neocriticista, cabe antes fazêlo surgir de seus próprios móveis internos, a partir das concepções de natureza humana e representação. Trata-se aqui de mostrar como a dualidade da natureza humana é condição para a viabilidade de uma sociologia das categorias, bem como sua relação com a teoria das representações coletivas.

No artigo que sucede a publicação das Formas, "O dualismo da natureza humana e suas condições sociais", de 1914, Durkheim sublinha um aspecto de sua obra que segundo ele passara despercebido pela crítica: a chave para a compreensão da origem da dualidade da natureza humana, expressa na imagem do homem como ser dividido entre corpo e alma, cisão constitucional que isola e opõe dois mundos distintos. De um lado, como emanações da base orgânica, as sensações e os apetites egoístas, de foro estritamente individuais; de outro as atividades do espírito, como o pensamento conceitual e a ação moral, necessariamente universalizáveis. Essa a fórmula do homo duplex (a expressão é do próprio Durkheim), constatação de um duplo centro de gravidade da vida interior: "Há, de um lado, nossa individualidade, e, mais especialmente, nosso corpo que a funda; de outro, tudo aquilo que, em nós, exprime outra coisa que não nós mesmos" 
(Durkheim 1970: 318). Antes de avançar uma solução para essa duplicidade, e em especial para a misteriosa expressão de "outra coisa que não nós mesmos", avalia as explicações disponíveis, reafirmando a realidade do dualismo ao afastar o monismo (tanto o empirista como o idealista) que vê aquele como simples aparência. Também a tese kantiana não o satisfaz: fundar o dualismo na existência simultânea de duas faculdades distintas, sensibilidade e razão, que dão conta respectivamente do particular e do universal, equivale a propor o dilema em outros termos sem no entanto resolvê-lo - o que só se dá pela explicitação de sua origem. Aqui é importante anotar que essa mesma estrutura da argumentação será mantida na crítica ao apriorismo das categorias; e, de resto, parace pautar a inteira relação da sociologia emergente com o discurso filosófico: a filosofia coloca as questões de modo pertinente, mas não é capaz de resolvê-las, via de regra porque desconhece a origem social da matéria em discussão.

De volta ao ponto, Durkheim quer explicar a origem da coexistência no mesmo ser de atitudes contrárias, e a própria adoção do método sociológico já antecipa sua solução. O espírito humano é um "sistema de fenômenos em tudo comparável aos outros fenômenos observáveis" (Durkheim 1970: 326). Tomado como coisa, objetivação que supera as idiossincrasias dos psiquismos individuais, ele revela através de sua origem na sociedade a sua verdadeira natureza. Durkheim associa a oposição encontrável nos fatos entre corpo e alma àquela que desenvolve nas Formas entre sagrado e profano. Existe uma hierarquia entre as funções psíquicas que redunda numa sacralização da alma em relação à pouca nobreza do corpo profano: "A dualidade de nossa natureza não é portanto senão um caso particular daquela divisão das coisas em sagradas e profanas que encontramos na base de todas as religiões, e ela deve se explicar segundo os mesmos princípios" (Id.:327). Ora, as coisas sagradas têm uma autoridade que impõe às vontades individuais como efeito da operação psíquica de síntese das consciências individuais em que se dá sua gênese. Os estados mentais gerados nesse processo encarnam-se em idéias coletivas que penetram as consciências individuais permitindo sua comunicabilidade. Para além das manifestações da biologia humana, esses estados da consciência “(...) nos vêm da sociedade; eles a traduzem em nós e nos atam a alguma coisa que nos supera. Sendo coletivos, eles são impessoais; eles nos dirigem a fins que temos em comum com os outros homens" (Id.: 328). A dualidade da natureza humana guarda uma homologia estrutural com a dualidade de fontes que conformam o homem; quais sejam, o corpo biológico e a sociedade. 
Ou, precisando melhor, a sociedade é a única fonte da humanidade do homem; é através dela que se transcende a pura vida orgânica que é a condição do homem tomado em sua individualidade. Apenas a vida coletiva faz do indivíduo uma personalidade, dando forma à consciência moral e pensamento lógico que têm origem e destinação social. O indivíduo não é ainda realidade humana, mas apenas abstração que só se perfaz no meio social. Antes de sua constituição na e pela força coletiva, não se pode falar propriamente de homem, mas de um ser que se reduz ao organismo animal. A humanidade do homem é coisa social, que se cristaliza por mecanismos de coerção. A sociedade, “(...)externa e transcendente ao indivíduo enquanto indivíduo, é interna e imanente ao indivíduo enquanto homem" (Vialatoux 1939: 18).

Assim, os conteúdos da mente desse homo duplex também estão cindidos quanto à sua gênese, e guardemos esta observação como via de entrada para o sistema das representações coletivas. Lukes (1984: 7), analisando os conceitos fundamentais do pensamento durkheimiano, alerta para a ambigüidade do termo "representação", que ora significa um processo de pensamento (ou da percepção) ora o conteúdo desse processo. Nessa flutuação, que adiante tratarei como herança neocriticista, estão inscritos o fundamento e o alcance de sua proposta epistemológica. Nesse ponto, vale salientar a presença em Durkheim de uma noção de representação em harmonia com a tradição filosófica com que dialoga: de modo geral, é representação como tudo aquilo que, afetando a mente ou emanando dela, é capaz de fixar-se com menor ou maior grau de estabilidade. No primeiro caso estão as representações sensíveis, que "encontram-se em fluxo perpétuo; empurram-se umas às outras como as ondas de um rio e, também enquanto duram, não permanecem iguais a si mesmas" (Durkheim 1989: 511). Já o pensamento conceitual ancora-se em representações coletivas, derivadas do fenômeno da associação entre homens.

$\mathrm{O}$ recurso à imagem da síntese química, tão freqüente em Durkheim, visa justamente dar o fundamento da independência relativa de uma representação em relação a seu substrato, e não por acaso é nuclear no artigo de 1898, "Representações individuais e representações coletivas". Nos dois tipos de representação, é por um processo de síntese que emerge uma realidade nova, irredutível aos elementos que estavam na base de sua gênese. Quanto às representações individuais, é a seguinte a formulação: "Com efeito, nada permite supor que uma representação, por muito elementar que seja, possa ser diretamente produzida por uma vibração celular (...) mas não existe sensação para a qual não contribua 
um certo número de células. Talvez mesmo o cérebro inteiro participe na elaboração de que elas resultam. É isso que o fato das substituições parece demonstrar. Em suma, parece ser essa também a única maneira de compreendermos como a sensação depende do cérebro, constituindo embora um fenômeno novo. A sensação depende porque é composta de modificações moleculares (...). Mas ela é simultaneamente coisa diferente já que resulta de uma síntese nova e sui generis em que essas modificações entram como elementos, mas onde são transformadas pelo simples fato de sua fusão" (Durkheim 1988: 199).

Pode-se manter a forma da argumentação para entender as representações coletivas como resultado do substrato dos indivíduos associados, o que parece expressamente autorizado: "A vida representativa não se pode repartir de uma forma definida entre os vários elementos nervosos, já que não existe representação para a qual não colaborem vários desses elementos, tal como a vida coletiva só pode existir no todo formado por reunião de indivíduos" (Durkheim 1988: 700). Síntese de elementos dispersos no meio social, as representações coletivas remetem à natureza supra-individual do homem, exprimem o ideal coletivo que tem origem na religião. São portanto impessoais e estáveis, comuns a todos na medida mesma em que emanam da comunidade dos homens; e, assim, instrumentos de intelecção do mundo e comunicação entre as razões individuais.

Para esta análise, é importante ressaltar que, assim concebidas, as representações coletivas são a um só passo a resultante da síntese dos indivíduos associados e a instância que dá forma a essa síntese. Na constituição da sociabilidade não é possível separar forma e conteúdo, já que essa opera sobre um conteúdo natural que não está dado, precisa ser constituído por uma virtude formalizadora que é imanente ao sujeito do processo, a própria sociedade. Para descrever o mecanismo desses momentos constitutivos da sociedade, Durkheim remete às efervescências do meio social, ou seja, momentos de intensificação dos elos entre os homens que geram periodicamente novas representações coletivas que são imediatamente incarnadas em um símbolo. Para fixar melhor o princípio desse simbolismo, tomo de empréstimo uma imagem de Giannotti (1980): em Durkheim, os fenômenos sociais não têm massa, não têm em si uma substância que garanta sua estabilidade - ou então a morfologia do meio social interno consistiria num substrato que só se modifica por pressão de forças externas a ele aplicadas. Mas, pelo contrário, a permanência dos fenômenos sociais depende de uma relação muito especial entre sua forma e conteúdo, de 
modo que a matéria social em si não perdura sem que sua forma lhe proponha um conteúdo adequado, capaz de sobrepor-se às coisas no momento da instituição do ideal.

O exemplo por excelência de como esse modelo adquire concretude está na teoria durkheimiana do totemismo, escolhido como objeto nas Formas justamente por concentrar a essência da religião, em que pese o preconceito envolvido na identificação da anterioridade lógica com o que seria historicamente primeiro. A passagem da horda primitiva, simples justaposição de indivíduos, para o clã totêmico supõe uma síntese dessas consciências individuais cujo produto sui generis é imediatamente hipostasiado no elemento natural simbólico que serve de totem. Ou seja, para que se efetive a constituição da primeira sociedade é necessário que a força dos homens associados se transfira idealmente a essa primeira representação coletiva para que adquira estabilidade, e entende-se porque a relação totêmica é pensada na forma específica de consubstancialidade entre os membros do grupo e o animal (ou elemento natural) epônimo. Não surpreende também que esse símbolo do grupo seja sacralizado - afinal, ele encarna nada menos do que a maior das forças encontráveis na natureza, a da associação dos homens.

A concepção durkheimiana do totemismo fornece, portanto, a estrutura básica da constituição do social, explicitando que um fenômeno social só se perfaz ao encarnar-se num símbolo. A religião ganha o peso de uma meta-instituição, manifestação originária da sociabilidade, e fonte de todo pensamento conceitual: as primeiras representações coletivas, necessariamente sacralizadas quando instituem o símbolo coletivo, empreendem a superação da profusão de sensações dadas à percepção justamente graças ao que Giannotti (1980) detectou como o fundo conceitual de toda representação, sua capacidade de remeter à totalidade. Só assim se faz possível um objeto cuja visão não seja puramente individual e portanto incomunicável, mas que, constituído por síntese coletiva, exprime uma atividade totalizadora que faz o objeto universalizável, capaz de atingir qualquer consciência individual. O desenvolvimento da sociologia das categorias está fundado na hipótese de que a categoria totalidade tem por substrato a própria sociedade. E, muito sintomaticamente, a totalidade ocupa o topo da hierarquia das categorias construída pelo neocriticismo. Podemos agora lançar nova luz à contraposição entre representações individuais e coletivas.

Em suma, toda representação é produto de uma síntese - sempre no sentido químico do termo - que lhe dá certa autonomia em relação a seu 
substrato. As representações individuais podem agora ser identificadas às sensações; têm por base o organismo sem corresponder direta e univocamente à determinação dos centros nervosos. A esse distanciamento Durkheim se refere como a espiritualidade característica dos fatos intelectuais. De outra espécie são as representações coletivas, que, urdidas através do meio social, identificam-se ao conceito. A remissão à natureza lingüística do conceito ratifica essa posição: “(...) não há dúvida de que a linguagem e por conseguinte o sistema de conceitos que traduz é produto da elaboração coletiva. O que exprime é a maneira pela qual a sociedade, no seu conjunto, concebe os objetos da experiência. As noções que correspondem aos diversos elementos da língua são portanto representações coletivas" (Durkheim 1989: 513). A espiritualidade que marca a vida representativa do indivíduo se desdobra quando da síntese das representações coletivas numa "hiperespiritualidade" maior que a pura soma das individualidades. Durkheim não hesita ante a conotação pouco científica do termo: “(...) não obstante o seu aspecto metafísico, o termo nada mais significa que um conjunto de fatos naturais que devem ser explicados por causas naturais" (Durkheim 1988: 207), o que reafirma o pressuposto da unidade da natureza, fazendo do homem a sede do cruzamento das propriedades pessoais do espírito com aquelas impessoais desse "hiperespírito" totalizante que transpõe para o primeiro aquilo que, nesse circuito, o constitui a própria sociedade.

Mas isso não deve ser interpretado como redução das representações coletivas às individuais: "se (os conceitos) são comuns a todo um grupo social, não significa que representem simples média entre as representações correspondentes, porque então seriam mais pobres que essas últimas em conteúdo intelectual, enquanto na realidade são plenos de um saber que ultrapassa o do indivíduo médio. São, não abstrações que só ganhariam realidade nas consciências particulares, mas representações tão concretas quanto aquelas que o indivíduo pode ter do seu meio social: elas correspondem à maneira pela qual esse ser especial, que é a sociedade, pensa as coisas de sua própria experiência” (Durkheim 1989: 513). Pensar conceitualmente rompe necessariamente a esfera do indivíduo, rebatendoo para a totalidade, já que a origem, os instrumentos e a destinação desse pensamento cobram sentido na realidade da vida coletiva. Conceitos são portanto representações coletivas. Essa formulação permite a Durkheim inscrever-se no debate filosófico a respeito das categorias do conhecimento. 


\section{REPRESENTAÇÃO E CATEGORIA}

A fundamentação social dos conceitos como representações coletivas, em contraponto às sensações individuais, ergue-se a partir da dualidade da natureza humana e tem por escopo nada menos do que uma ontologia do social, conforme a análise precedente. Nas Formas, a preocupação mais imediata de Durkheim, que não difere desta, é provar que também as categorias do conhecimento conforme pensadas por Kant são na realidade representações coletivas. Com isso o ímpeto demarcatório de um campo próprio à sociologia destaca-se da fronteira com a psicologia para uma disputa com a filosofia, cujo terreno, consolidado por uma tradição de séculos, demandava um assalto que o tomasse por inteiro, subordinando-o ao raciocínio experimental. Como estratégia de combate, Durkheim seleciona o problema mais relevante colocado pela discussão filosófica para mostrá-lo estéril se tomado em seus próprios moldes, para então fecundálo com o condão que só a aproximação sociológica teria, a de expor seu impasse e solucioná-lo. É com esse objetivo que Durkheim revê a polêmica empirismo versus apriorismo pensando as categorias como representações coletivas. Nesse movimento revela-se o esteio kantiano e neocriticista de suas posições, conforme cumpre examinar.

Há em Durkheim uma relação de contigüidade entre conceito e categorias, sendo estas espécies mais essenciais de conceito, porque, "Na raiz dos nossos julgamentos (....) dominam toda nossa vida intelectual." (Durkheim 1989: 38). Categoria é o conteúdo expressivo dos conceitos mais gerais, noções essenciais objetivas e necessárias que configuram a “ossatura da inteligência” (Durkheim 1989: 46), cuja função é "dominar e envolver todos os outros conceitos", como "quadros permanentes da vida mental" (Durkheim 1989: 518). Assim, a mesma argumentação a respeito da origem social dos conceitos pode ser imediatamente transposta para as categorias, que são deduzidas como representações coletivas que têm sua gênese na religião. A determinação social das categorias serve como instrumento para superar o dilema empirismo versus apriorismo. As duas doutrinas mostram-se insuficientes no diagnóstico de Durkheim. O empirismo, derivando as categorias da experiência sensível, não pode dar conta de sua universalidade e necessidade . Já o apriorismo admite o caráter apodítico das categorias, mas limita-se a postulá-lo sem explicação, incorrendo portanto numa petição de principio. Transpostas para a ciência positiva dos fatos sociais, as velhas questões epistemológicas podem conservar seu apreço pelo poder da razão sem sair do universo observável da experiência. Nesse 
movimento, o racionalismo militante de Durkheim parece conciliar o melhor de dois mundos opostos: evita a crença empirista de que uma categoria possa se originar de um conjunto de representações sensíveis individuais generalizáveis, preservando assim seu caráter universal e necessário, conforme o apriorismo havia desenvolvido. Mas retira do transcendente o espaço próprio da gênese das categorias, fundando-as no real, embora numa nova ordem do real, a existência coletiva. Revestindo as categorias do caráter positivo das representações coletivas, portanto do âmbito dos fenômenos sociais, Durkheim as funda na natureza e recupera seu vínculo empírico.

Pensar as categorias como representações coletivas dá a Durkheim a possibilidade de avançar do ponto em que Kant havia se detido, introjetando como legítima a estrutura de uma epistemologia conforme erigida pelo filósofo, que serve como ponto de partida e referência permanente para o avanço da sociologia. Esta, apontando a matriz social das questões relativas ao conhecimento, deve tomá-las como objeto. A tentativa de uma epistemologia sociológica surge como resposta ao kantismo, mas é tributária de sua vertente francesa. Para compreender adequadamente essa passagem, é preciso retomar brevemente as notas essenciais da teoria kantiana do conhecimento.

Nesse sistema, tempo e espaço são concebidos como formas dadas a priori da sensibilidade, a faculdade passiva que recebe as afecções produzidas pelo objeto acomodando-as imediatamente ao registro da conformação interna do sujeito. A partir dessa recepção material das coisas o conhecimento racional surgirá como síntese de sensibilidade e entendimento - este último a faculdade ativa que media a referência do pensamento ao objeto. Tempo e espaço são portanto condições gerais de todo conhecimento, que submetem necessariamente toda a experiência na geração de novos conhecimentos. Essa submissão necessária do objeto ao sujeito configura aquilo que Kant chamou de "revolução copernicana" do pensamento. $\mathrm{O}$ fato de que as formas da sensibilidade, que dão unidade à matéria posta diante da percepção sempre como múltiplo, sejam uma realidade interna do sujeito, embasa a intercisão das coisas em fenômenos e coisa em si. O fenômeno é o objeto posto no tempo e espaço por uma operação inescapável, assim que é dado à intuição sensível de um ser racional. Desse modo, tudo que é possível conhecer só o é sob a forma de fenômeno, já que das coisas em si, livres da conformação imposta pela estrutura interna da sensibilidade, nada é possível saber. Tempo e espaço não são, portanto, representações que surgem da experiência, mas algo que está dado 
em leis do espírito que são formas funcionais da mente racional, e, nesse aspecto, antecipam a própria experiência enquanto condição lógica de sua constituição. De outra natureza são as categorias, conceitos puros do entendimento, dados também a priori, que têm por fonte a atividade da razão.

Parece clara a inspiração kantiana de Durkheim, ao pensar formas e categorias nos marcos de uma fundamentação do conhecimento, cujo desenvolvimento seguirá um outro rumo. Apartir da identidade formal, funcional e genética das representações coletivas com as categorias, Durkheim elide o corte entre sensibilidade e entendimento subsumindo à mesma rubrica tempo, espaço e categorias kantianas como causalidade, gênero, substância, totalidade; entendendo que desempenham o mesmo papel na atividade intelectual, e evocando para corroborar sua posição o amparo do "Essai sur les éléments principaux de la represéntation", de Octave Hamelin, a que voltarei adiante. Nesse aspecto, a astúcia de Durkheim consiste em simplesmente assimilar o problema das categorias ao processo coletivo de representação para derivá-las empiricamente de determinações próprias da sociedade. E como um objeto eminentemente social só é passível de apropriação legítima pela sociologia, o discurso filosófico torna-se inoperante na questão. Historicamente, esse projeto abriga-se no contexto do impacto que a consolidação das ciências, e em especial da ciência positiva dos fatos sociais, têm sobre a filosofia pensada como uma teoria da totalidade dos entes e sua representação. A constituição de ontologias regionais a respeito do mundo passa para o domínio das ciências que se autonomizam, reivindicando para si a primazia de uma notação crível do real porque empiricamente demonstrável. Assim, está implícito na redução social das categorias que um saber sobre o conhecimento é um saber sobre o mundo, e a proposição da sociedade como seu espaço de constituição lógica remete à clivagem de uma região estipulável pela ciência.

No entanto, e é aqui que intervém decisivamente a influência do neocriticismo, Durkheim só pode reduzir socialmente as categorias levando em conta a plasticidade daquilo que entende por representação, que comportaria o que Lukes captou como imprecisão semântica: uma representação coletiva é, a um só tempo, um processo e seu conteúdo. A comprovação da natureza social das categorias baseia-se na transposição dessa ambigüidade, de modo que basta expor o substrato social das categorizações para inferir que categorias são em si coisa social.

Esse princípio já estava presente no artigo de 1903, “Algumas formas primitivas de classificação", escrito em colaboração com Mauss, que consolida o sistema social como fundamento do sistema lógico, 
mostrando como as classificações são objetivações das determinações próprias da sociedade, ou seja, são decalque da vida social. O último parágrafo desse artigo enuncia de modo eloqüente o programa a ser seguido pela sociologia a partir da ênfase nas representações coletivas como seu objeto preferencial: "Pode-se ver (...) com que luz a sociologia ilumina a gênese e, por conseguinte, o funcionamento das operações lógicas. Aquilo que procuramos fazer para a classificação poderia também ser tentado para as outras funções ou noções fundamentais do entendimento. Já tivemos ocasião de indicar, no decurso do trabalho, de que forma idéias tão abstratas como aquelas de tempo e espaço se acham a cada momento de sua história em íntima relação com a organização social correspondente. $\mathrm{O}$ mesmo método poderia também ajudar a compreender a maneira pela qual se formaram as idéias de causa, de substância, as diferentes formas de raciocínio etc. Todas estas questões, que metafísicos e psicólogos desde há muito ventilam, serão enfim libertadas das repetições em que se detêm, no dia em que forem formuladas em termos sociológicos. Aí existe ao menos um caminho novo que merece ser tentado" (Mauss 1981: 455). A tentativa de um "caminho novo" se converteria num projeto que implica a postulação definitiva da legalidade do discurso sociológico. Do fato, tido no artigo como empiricamente constatado, de que algumas classificações primitivas estejam calcadas na estrutura social (ainda com grande peso para a morfologia, mas já levando em conta o simbolismo coletivo), Durkheim infere que os operadores lógicos movimentados nesse processo têm também origem social. Ou seja, se uma determinada tribo está territorialmente disposta de modo circular, é de se esperar que as espacializações engendradas por seus membros obedeçam a um princípio de circularidade, e isso seria prova - se levarmos até o fim o argumento durkheimiano - de que o espaço em si é algo social. É sobre essa passagem que incide uma crítica como a de Torre (1989), em plena harmonia com a de Lukes: da constatação que categorizações podem estar socialmente fundadas não segue que categorias também estejam, tanto é assim que Durkheim oferece provas à primeira parte do argumento, mas não à segunda, que decorre arbitrariamente.

De todo modo, nas Formas Durkheim leva a efeito o que enunciara quase dez anos antes. De um lado localiza definitivamente a autoridade da razão como extensão objetivada da autoridade da sociedade: "A necessidade com que as categorias se impõem a nós não é, portanto, efeito de simples hábitos cujo jugo poderíamos eliminar com um pouco de esforço; e menos ainda da necessidade física ou metafísica, já que as categorias mudam com os lugares, os tempos; trata-se de uma espécie particular 
de necessidade moral que é para a vida intelectual o que a obrigação moral é para a vontade" (Durkheim 1988: 47). De outro, indica o substrato social de algumas categorias, a serem investigadas por sociologias regionais que, integradas, edificariam a almejada epistemologia sociológica: o esboço de um sistema das categorias das Formas indica na base da categoria de classe a classe social; na de totalidade, a sociedade; na de gênero, o grupo humano; na de força eficaz, a força coletiva; na de espaço, o território; e, finalmente, na de tempo, o ritmo da vida coletiva. Através desse esquema, Durkheim instaura, por exemplo, o tempo em si como algo de natureza social a partir da constatação de que o ritmo da vida coletiva informa temporalizações que operam na sociedade. Não há dúvida, nesse ponto, que isso envolve o uso indiscriminado da noção de representação como forma e conteúdo ou, homologamente, de categoria e categorização. Mas, ao invés de referendar simplesmente as críticas à impropriedade lógica da operação, é mais fecundo desvelar sua origem através do exame, em seus contornos essenciais, do significado social e teórico do neocriticismo e seu impacto sobre Durkheim.

A doutrina neocriticista alicerça a adoção do racionalismo kantiano pela reforma educacional da III República, que visava à formulação de uma moral laica. A afirmação da autonomia da razão é portanto estratégica para o novo regime, permitindo evitar os equívocos advindos da união perversa entre catolicismo e monarquia, a que Charles Renouvier, conhecido como "o Kant republicano" e principal nome no grupo, imputa a derrota sofrida pela França diante da Alemanha em 1870. Mas, para que tal doutrina possa servir de instrumento para a ação humana sobre o mundo, é-lhe necessário quebrar a rigidez do quadro categorial kantiano em que se inspira, modificando alguns de seus supostos no sentido de estender os ideais críticos para além dos limites originais. Assim também na leitura de Cardoso de Oliveira, em que a vertente neocriticista interpreta restritivamente o apriorismo das categorias e das formas da sensibilidade, subordinando a razão teórica à razão prática, “(...) num claro fortalecimento do papel da vontade e da escolha na constituição da Razão, no que diz respeito aos princípios fundamentais que ordenam a noção de experiência. Tal restrição poderia ter sido responsável pelo direcionamento da pesquisa durkheimiana na busca da constituição de uma epistemologia sociológica" (Cardoso de Oliveira 1988). O encaminhamento que dou à análise implica claramente a assunção da sugestão destacada do texto de Cardoso de Oliveira, cuja pertinência só pode fixar-se na reconstituição do que há de inovador nessa particular apropriação do kantismo. 
A leitura que fazem de Kant seus discípulos franceses tem como eixo central a proposição de uma nova relação entre teoria e prática, admitindo uma interferência entre os dois domínios, o que implica colocar o problema das categorias imbricado com a constituição do sistema moral, esforço que corresponde ideologicamente à urgência de expandir a crítica kantiana no intuito de torná-la instrumentalizável para a ação humana na história, dada a necessidade de legitimação de um novo ideal político que é comum a Durkheim. É sob o crivo desse eixo teórico que se compreende os dois supostos básicos do sistema de Renouvier, o fideísmo e o relativismo. $\mathrm{O}$ primeiro concede à crença o estatuto de verdade teórica, desde que essa crença possa ser tida como racional porque fundada em um juízo do entendimento. $\mathrm{O}$ recurso à crença racional, que suprime a autonomia que a razão tem em Kant, apóia-se no relativismo que recusa a postulação de qualquer princípio incondicionado ou absoluto como solo da razão, afirmando a existência do real unicamente por meio de relações entre termos que possam ser objeto de demonstração. A partir disso impõe-se eliminar a divisão das coisas entre fenômenos e coisa em si: toda realidade é fenomênica, dada a recusa em postular um termo absoluto com anterioridade lógica à sua relação com outro termo. Para Renouvier, "a representação do real é todo o real e, como representação é relação, o real é um tecido de relações" (Leopoldo e Silva 1980: 111). Se não há realidade para além da representação, as categorias não têm apenas uma natureza transcendental e função meramente reguladora como em Kant, mas são também determinação das coisas, o que as faz transitar pelo domínio do ser.

O trabalho mencionado de Hamelin a que Durkheim recorre nas Formas, publicado em 1907, consolida definitivamente essa nova concepção. Já a partir do título, Hamelin prefere a fórmula "elementos principais da representação" a categorias, rubrica comum que engloba estas e as formas da sensibilidade. Fiel aos princípios desenvolvidos por Renouvier para uma apropriação do pensamento de Kant que o torne adequado às necessidades práticas e teóricas do neocriticismo, o livro trata de compor um quadro geral das categorias obtidas dialeticamente a partir de sínteses de elementos contrários cujas relações integram a totalidade do sistema. Pode-se entender a obra de Hamelin como ratificação do movimento iniciado por Renouvier na direção de suprimir duas séries de cortes que orientavam a crítica kantiana, entre fenômeno e coisa em si e entre sensibilidade e entendimento. Tal superação resulta numa noção de representação que amplia a função das categorias para além do uso transcendental que Kant lhes consagrara. Hamelin trata de explorar as consequências dos funda- 
mentos do sistema de seu mestre no que concerne ao desenvolvimento de um novo estatuto para as categorias. Concebendo o mundo como um conjunto de relações entre termos que não subsistem por si mesmos como absolutos dados antes dessas relações, as categorias são tidas como elementos mesmos dessas relações, e não como simples condição formal de sua possibilidade. Em outros termos, se o conhecimento se faz por meio de sínteses, as categorias são as leis que regem a síntese, mas são também seres presentes nela, elementos primitivos e reais que operam as leis fundamentais da representação. Da leitura do "Essai sur les éléments principaux de la réprésentation" depreende-se a chancela de uma dupla natureza conferida às categorias pelo neocriticismo, que as compreende a um só tempo no âmbito transcendental e fenomênico, como condição de possibilidade do processo de conhecimento e como determinação das relações em jogo nesse processo. É assim que as leis são os seres, e o termo representação pode significar o ato lógico de representar e o produto desse ato: "Contrariamente ao significado etimológico, representação não representa, não reflete um objeto e um sujeito que existiriam sem ela, ela mesma é objeto e sujeito, ela é a realidade mesma" (Mora 1951: 800). Ou, numa formulação mais sintética mas não menos lapidar: "A representação é o ser, e o ser é a representação" (Mora 1951: 800).

Percebe-se então o quanto os discípulos franceses de Kant afastam-se dele na reinterpretação de sua obra, que busca apoio para o conhecimento fora de si mesmo, derivando a certeza da consciência moral, supondo a autonomia da razão prática - só assim a vontade ganha peso diante da razão, e isso garante ao homem a possibilidade de "(...) livremente representar, imprimindo modificações à vida e aos acontecimentos" (Leopoldo e Silva 1980: 71). Trazendo a atenção de volta para a teoria durkheimiana da representação, não parece haver dúvida de que ela é inteiramente tributária dessa razão neocriticista, que lhe empresta a matriz que possibilita pensar as representações coletivas como forma e conteúdo, como sujeito e objeto do mesmo processo. Impõe-se, assim, que se reconfigure as críticas do suposto erro lógico em que Durkheim incorreria ao pensar categorias a partir de categorizações, que redundaria na imprecisão semântica do uso do termo representação, que Lukes aponta. É fundamental, nesse sentido, assinalar que Durkheim não confunde os usos transcendental (como condição de possibilidade do conhecimento) e fenomênico (como determinação das coisas) das categorias; deliberadamente ele os funde, seguindo de perto o pensamento de Hamelin, de quem fora contemporâneo como professor em Bordeaux, época em que se estreitaram com 
intensidade os laços intelectuais e pessoais entre eles. O relevo dado à razão prática resultou para os neocriticistas nessa fluidez plástica das categorias, que rompe a rigidez formal de que Kant as investira, oferecendo a Durkheim a possibilidade de dar o passo que considera definitivo, pensando as categorias como socialmente determinadas. A necessidade dessa passagem remete à superação do debate entre empirismo e apriorismo: afinal, se o neocriticismo havia dado fundamento à dupla natureza das categorias, ainda abrigava-se sob a crítica genérica de Durkheim a todo apriorismo, descrevendo corretamente essa natureza mas postulando-a sem explicar sua origem. Uma vez incorporada a nova concepção de categoria era preciso dar-lhe o fundamento, e sabemos já que Durkheim recorre à identificação das categorias como representações coletivas, garantindo assim a superação do velho dilema, fundando as categorias como expressão da natureza empírica e a priori do objeto que representam, a própria sociedade, numa argumentação cuja lógica procurei desenvolver anteriormente. De todo modo, para afirmar que as categorias mudam conforme os grupos sociais, estando portanto socialmente determinadas, Durkheim não faz outra coisa senão adotar com toda radicalidade o caráter contingente da razão neocriticista: a montagem da epistemologia de Renouvier supõe que as categorias poderiam ser outras (lembremos o papel decisivo que é dado à vontade e à escolha na constituição da razão que ordena a experiência, donde o privilégio dado à razão prática).

Seria difícil exagerar a influência que Durkheim sofre dos neokantianos franceses. Veja-se como ilustração a reverência com que se refere a Renouvier, em carta endereçada a Maublanc: "Se desejas aperfeiçoar teu pensamento, consagra-te ao estudo de um grande mestre, desmonte as peças de um sistema, descobrindo seus mais íntimos segredos. Foi o que fiz e meu mestre foi Renouvier" (Lukes 1984: 99). Mesmo ao distanciar-se do sistema de seu mestre, fundando as categorias na experiência coletiva, parece seguir uma pista sugerida por ele. Lembremos que, para Renouvier, não existe o noumeno, a coisa em si, e para além de um fenômeno há apenas "outros fenômenos, segmentos mais abrangentes do mundo empírico, novas multiplicidades não acessíveis à experiência imediata. A síntese total sob categorias, se fosse possível, seria fenomênica" (Leopoldo e Silva 1980: 114). A categoria é também um fenômeno, mas de tal generalidade que não pode reduzir-se à cadeia empírica que a precede. Se a síntese sob categorias é fenomênica, ela é maior do que a pura soma dos elementos dispersos na experiência. Desse modo, para Durkheim o segmento mais abrangente do mundo empírico é a experiência coletiva, a 
categoria totalidade tem por substrato a própria sociedade e toda categoria, como representação coletiva, é resultado de uma síntese sui generis a partir do fato dos homens associados, sem possibilidade de remissão à consciência individual.

De certo modo, a teoria das representações coletivas, esteio da nova epistemologia sociológica, aproveita a estrutura do sistema de Renouvier modificando-lhe o conteúdo, ao conceber categorias como representações coletivas. Mas essa passagem tem para Durkheim a dimensão de ato fundante de uma nova ordem intelectual. Rebatendo as categorias para o plano da sociedade, a sociologia desponta como a disciplina a que caberia por direito tratar das questões epistemológicas. Mais que a superação do dilema empirismo versus apriorismo, a manobra de Durkheim visa superar a filosofia por dentro de seu campo, como vimos. Do ponto de vista da contribuição à sociologia contemporânea, torna-se irrelevante discutir se logrou fazê-lo. Mais importante é salientar que, nessa tentativa, abre espaço para pensar o plano simbólico não como reflexo, mas como instituinte da realidade social.

FERNANDO PINHEIRO FILHO é professor de Sociologia da Fundação Escola de Sociologia e Política de São Paulo.

\section{REFERÊNCIAS BIBLIOGRÁFICAS}

CARDOSO DE OLIVEIRA, R. (1988). Sobre pensamento antropológico. Rio de Janeiro, Ed. Tempo Brasileiro.

DURKHEIM, É. (1970). Sociologia e filosofia. São Paulo, Ed. Forense. (1970). La science sociale et l'action. Paris, Presses Universitaires de France. (1975). Textes vol. 2 - réligion, morale, anomie. Paris, Les Editions de Minuit. (1988). Pragmatismo e sociologia. Porto, RES Editora. (1989). As formas elementares de vida religiosa. São Paulo, Edições Paulinas. (1990). As regras do método sociológico. São Paulo, Cia. Editora Nacional.

FERRATER MORA, J. (1951). Diccionario de filosofía. Buenos Aires, Editorial Sudamericana. FERNANDES, F. (1978). Fundamentos empíricos da explicação sociológica. Rio de Janeiro, Livros Técnicos e Científicos Editora.

GIANNOTTI, J. (1980). Exercícios de filosofia. Petrópolis, Ed. Vozes.

HALBWACS, M. (1990). A memória coletiva. São Paulo, Ed. Vértice.

HAMELIN, O. (1925). Essai sur les éléments principaux de la réprésentation. Paris, Librarie Félix Alcan.

LEOPOLDO E SILVA, F. (1980). Elementos para a imagem moral do homem na filosofia francesa do final do século XIX e início do séculoXX. Tese de doutoramento, FFLCH/USP.

LUKES, S. (1984). Émile Durkheim su vida y su obra. Madrid, Centro de Investigaciones Sociologicas/Siglo XXIde España Editores. 
MAUSS, M. (1981). Ensaios de sociologia. São Paulo, Ed. Perspectiva.

TORRE, R. (1989/1990). "El calendario sagrado - el problema del tiempo en la sociologia durkheimiana”. In: Revista Española de Investigaciones Sociales, nros. 46, 48 e 49. Madrid.

VIALATOUX, J. (1939). De Durkheim à Bergson. Paris, Bloud \& Gay. 